\title{
Experimental Analysis of Hybridised Energy Storage Systems for Automotive Applications
}

\author{
Wasim Sarwar ${ }^{1 *}$, Timothy Engstrom ${ }^{1}$, Monica Marinescu ${ }^{1}$, Nick Green ${ }^{2}$, Nigel \\ Taylor ${ }^{2}$, Gregory J Offer ${ }^{1}$ \\ ${ }^{1}$ Department of Mechanical Engineering, Imperial College London, UK \\ ${ }^{2}$ Hybrids and Electrification Research, Jaguar Land Rover, Warwick, UK \\ * Contact details of corresponding author: \\ w.sarwar@imperial.ac.uk / +44 7894556476
}

Keywords: Hybridised Energy Storage, Lithium Battery, Supercapacitor, Automotive, Degradation, Passive

\section{Highlights}

- Hybridised system is shown to perform similarly to a specialised high power battery

- Hybridised system exhibits lower temperature sensitivity than battery only systems

- Battery current and energy throughput reduced by over $80 \%$ in hybridised system

- Degradation occurs at a similar rate for all systems tested

- Battery current demand and temperature rise reduce as hybridised system degrades

\begin{abstract}
The requirements of the Energy Storage System (ESS) for an electrified vehicle portfolio consisting of a range of vehicles from micro Hybrid Electric Vehicle (mHEV) to a Battery Electric Vehicle (BEV) vary considerably. To reduce development cost of an electrified powertrain portfolio, a modular system would ideally be scaled across each vehicle; however, the conflicting requirements of a mHEV and BEV prevent this. This study investigates whether it is possible to combine supercapacitors suitable for an $\mathrm{mHEV}$ with high-energy batteries suitable for use in a BEV to create a Hybridised Energy Storage System (HESS) suitable for use in a HEV. A passive HESS is found to be capable of meeting the electrical demands of a HEV drive cycle; the operating principles of HESSs are discussed and factors limiting system performance are explored. The performance of the HESS is found to be significantly less temperature dependent than battery-only systems, however the heat generated suggests a requirement for thermal management. As the HESS degrades (at a similar rate to a specialised high-power-battery), battery resistance rises faster than supercapacitor resistance; as a result, the supercapacitor provides a greater current contribution, therefore the energy throughput, temperature rise and degradation of the batteries is reduced.
\end{abstract}




\section{Nomenclature}

\begin{tabular}{|c|l|c|l|}
\hline A, B & Experimentally derived constants & $I_{T}$ & Total applied current \\
\hline ATM & Active Thermal Management & I2kF & loxus 2000F Supercapacitor \\
\hline BEV & Battery Electric Vehicle & I3kF & loxus 3000F Supercapacitor \\
\hline CTR & Charge Transfer Resistance & mHEV & micro Hybrid Electric Vehicle \\
\hline EIS & Electrochemcial Impedance Spectroscopy & $n$ & number of cells \\
\hline ESR & Equivalent Series Resistance & NEDC & New European Drive Cycle \\
\hline ESS & Energy Storage System & P18650BD & Panasonic 18650BD Cylindrical Cell \\
\hline ET & Energy Throughput & PHEV & Plug-in Hybrid Electric Vehicle \\
\hline FTP & Federal Test Procedure & $\dot{Q}_{\text {El_Loss }}$ & Rate of heat generation due to electrical \\
\hline HEB & losses \\
\hline HESS & Hybridised Energy Battery & R & Resistance \\
\hline HEV & Hybrid Electric Vehicle & SC & Supercapacitor \\
\hline HPB & High Power Battery & SEI & Solid Electrolyte Interphase \\
\hline$I_{0_{\text {Batt }}}$ & Instantaneous battery current in HESS & SOC & State of Charge \\
\hline$I_{0_{S C}}$ & Instantaneous SC current in HESS & ULTP & Wrban Dynamometer Driving Schedule \\
\hline$I_{\text {Batt }}$ & Battery current in HESS & $\eta$ & Overpotential \\
\hline
\end{tabular}

Table 1: Nomenclature

\subsection{Introduction}

It is desirable for an automaker to create a modular electrified powertrain to enable the usage of the same base components across its portfolio of vehicles. The energy and power requirements of the Energy Storage System (ESS) vary significantly for different vehicle types; the requirements are summarised in Figure 1.

\begin{tabular}{|c|c|c|c|c|}
\hline $\mathrm{mHEV}$ & HEV & & PHEV & BEV \\
\hline $0.1-0.2$ & $1.5-4$ & Energy (kWh) & $8-18$ & $25-90$ \\
\hline $8-16$ & $15-60$ & Power (kW) & $40-100$ & $50-450$ \\
\hline $40-160$ & $10-40$ & Power Density (W/Wh) & $6-20$ & $2-5$ \\
\hline $150-300$ & $30-60$ & Cycle Life (000's) & $4-10$ & $0.8-2$ \\
\hline Passive & Semi-Active & Thermal Management & Active & Active \\
\hline
\end{tabular}

Figure 1: Energy storage system requirements for electrified vehicles that fall under the broad categories of $\mathrm{mHEV}, \mathrm{HEV}$, PHEV and BEV. In addition to a numerical quantification of the requirement, a colour scale indicates the most challenging factors in the design of an energy storage system for the particular application. The scale passes from green to red, with green requirements proving the least challenging for traditional battery technology, and red requirements the most challenging. Sources - [1-14] 
Vehicles classified as micro Hybrid Electric Vehicles (mHEVs) typically utilise low voltage (48V) energy storage to enable high power functions and features to reduce $\mathrm{CO}_{2}$ emissions, such as electronic Power Assisted Steering, electric turbocharging, capturing regenerative energy from the vehicle, and enabling the engine to be switched off for extended periods of time. The ESS in a mHEV must provide or accept very high power for its size (commonly refereed to as 'C-Rate') for short time periods with minimal thermal management (passive cooling), therefore it must have the attributes of high power, low energy, large thermal operating window, and high cycle life.

Hybrid Electric Vehicles (HEVs) can be electrically propelled for short distances and require significantly more power than a mHEV, therefore HEVs typically utilise high voltage ESSs (200-450V). A HEV is less cost sensitive than the mHEV, therefore semi-active thermal management (indirect liquid cooling) can be used to improve system performance. Additionally, the usage profile dictates a lower cycle requirement than a $\mathrm{mHEV}$ as the larger energy capacity ESS is subject to fewer cycles for a given driving distance. Plug-in Hybrid Electric Vehicles (PHEV) have a similar use-case to HEVs, however they must electrically propel the vehicle for longer distances and therefore require more energy and consequently lower power density. Greater value exists in thermal management of larger battery packs, therefore the required thermal operating window is smaller.

Battery Electric Vehicles (BEVs) require significantly more energy and power than PHEVs, consequently larger ESSs are used. As with PHEVs, in a large ESS the use of active thermal management (system consisting of heating and cooling loop) provides good value, therefore a large thermal operating window is not required. Further, a comparatively shorter cycle life is sufficient in order to meet the vehicle life requirements.

As the requirements of the ESS for each vehicle configuration differ, it follows that a different battery or EDLC cell would be implemented in a module for each. However, the research and development required for the implementation of previously unused cells is costly, resource intensive and highly time consuming. It is therefore desirable to commonize cells across vehicle types.

SCs or High Power Battery (HPB) cells can be used to satisfy the requirements of an mHEV, and High Energy Battery (HEB) cells can fulfil the requirements of a BEV. Whilst it is not possible to use the same cells for a mHEV and BEV given the mutually exclusive attributes required, it is postulated that the cells for the $\mathrm{mHEV}$ and BEV could be combined to create a Hybridised Energy Storage System (HESS) for use in HEV and PHEV vehicles. This would enable automotive OEMs to adopt a modular approach whereby high energy and high power cells can be combined and their relative numbers scaled to meet the requirements of different vehicles.

Relatively few studies have analysed combinations of batteries and SCs for use in automotive applications [15-34], and a smaller number yet examine automotive traction applications, $[23,25,30,31,34]$. The studies that have considered traction applications do not consider practical requirements in hybrid vehicles, such as cost, volume, mass and reliability, and thus typically employ high cost and low reliability high power bi-directional DC-DC converters.

It is hypothesised that a combination of SCs and HEBs can reproduce the electrical capabilities of a HPB in automotive applications, whilst increasing energy efficiency, thereby reducing thermal management requirements and battery degradation. This study aims to quantify the electrical, thermal and degradation benefits of a HESS suitable for practical implementation into a HEV 
application against a specialised Energy Storage System (ESS), whilst considering cost, size and volume.

\subsection{Evaluation Conditions}

\subsection{Drive Cycle Selection}

For meaningful and repeatable results, all comparisons are made using an automotive drive cycle. The NEDC drive cycle has a combination of very slow acceleration, constant velocity operation and long idle times compared to FTP-72, the drive cycle currently used for fuel economy and emissions certification in the US market. Although the RMS current required for a HEV to meet the demand of the NEDC and FTP-72 drive cycles is similar ( 25 vs 28.5 ), a comparison of Figure $2 \mathrm{a}$ and Figure $2 \mathrm{~b}$ demonstrates that the current demand for the FTP drive cycle contains peaks of significantly larger amplitude and frequency. The FTP cycle is considered a better representation of real world usage.
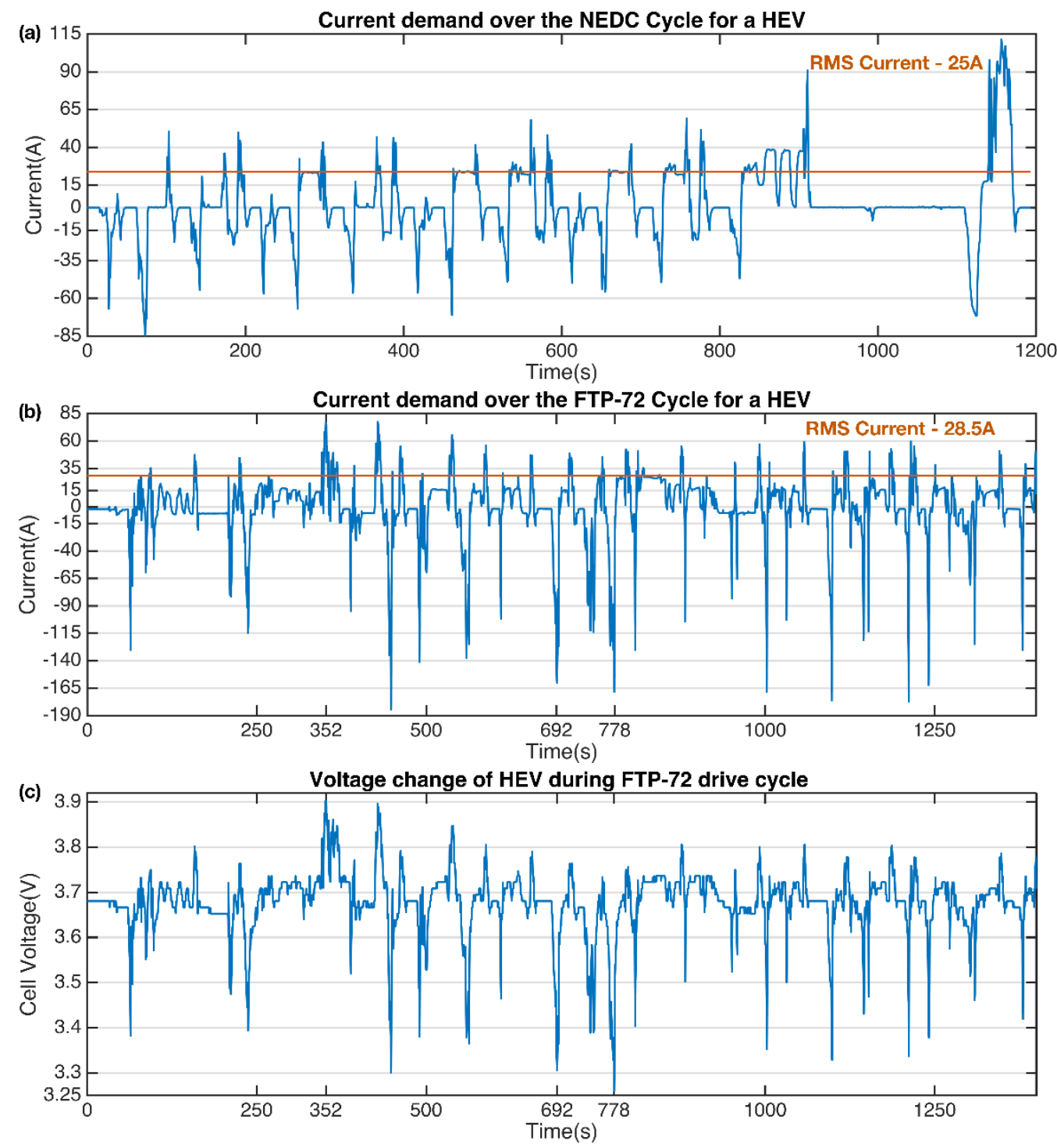

Figure 2: (a) Current request of a HEV during the NEDC drive cycle - orange line indicates the RMS current (25A), (b) Current request of a HEV during the FTP-72 drive cycle - orange line indicates the RMS current (28.5A), (c) Voltage evolution of a high power battery cell during the FTP drive cycle - Initial Conditions: $3.68 \mathrm{~V}, 25^{\circ} \mathrm{C}$ 


\subsection{Drive Cycle Analysis}

The Federal Test Procedure 75 (FTP-75) driving cycle is used by the Environmental Protection Agency (EPA) to determine the 'city driving' fuel efficiency for the US market and is widely regarded as representative of real world driving, [35,36]. The FTP-75 drive cycle consists of three distinct sections, the cold start phase (505s in duration), the stabilisation phase (866s in duration) and the hot start phase (505s in duration), which is a repetition of the cold start phase, [36]. Given that the objective of this work is capability analysis, the drive cycle is truncated by removing the hot-start phase to reduce cycle time without compromising the potential for performance analysis. The truncated version of the FTP-75 drive cycle is known as the FTP-72 drive cycle or the Urban Dynamometer Driving Schedule (UDDS).

The FTP-72 drive cycle is 1369s in duration, covering a distance of $12 \mathrm{~km}$ at an average speed of $31.5 \mathrm{~km} / \mathrm{h}$. The current demand and cell voltage shown in Figure $2 \mathrm{~b}$ and Figure $2 \mathrm{c}$ is measured from a HEV and is dynamically controlled by the Vehicle Supervisory Controller (VSC) for the particular vehicle requirements and a particular ESS, and therefore should only be used as an indicative requirement. This current demand profile is utilised for all ESSs tested in this work to ensure all are comparable to a baseline. Power availability is of greater importance than energy capacity for the drive cycle.

\subsection{System Configuration}

A HESS consisting of SCs and batteries can adopt multiple topologies; these topologies can be categorised as active, semi-active or passive. Passive systems combine SCs and batteries in parallel and do not employ any direct control of the current provided by each device, $[37,38,27,39,26]$. Semiactive systems use a DC-DC converter to control the power contribution of either the SCs $[32,40]$ or batteries [41,42]. A fully active system uses two DC-DC converters to independently control the power contribution of both the SCs and batteries, [43,44]. Multiple authors have worked to design bi-directional DC-DC converters specifically for the HESS application, [45-47]. Graphical representations of each configuration can be found in the review conducted by Kuperman et al, [48]

\subsection{Passive HESS}

In passive systems, SCs and batteries are connected in parallel with one another, and the output of the parallel string is connected to the load. The current split between the battery and the SC is controlled by the relative resistance of each device, and cannot be actively controlled. The passive configuration does not require any control electronics unlike semi-active and fully active systems and is therefore in general the most robust, the cheapest, and requires the least package volume. Over a pulsed discharge, a passive HESS reduces battery current and voltage fluctuations thereby increasing energy efficiency and reducing battery degradation. However, the contribution of battery current to a current pulse does increase with pulse duration due to the SC voltage changing faster than the battery voltage when energy is added or removed. As a result, both the battery current rating and the $\mathrm{SC}$ energy capacity are factors that limit the maximum duration of a pulse that can be sustained. In this configuration, only a small fraction of the energy capacity of the SC is used, and the upper voltage limit of the $\mathrm{SC}$ bank and battery module must match. Whilst this system provides the fewest performance benefits, it is the cheapest, least complex and most reliable, [48]. 


\subsection{Semi-active HESS}

The most common semi-active HESS topologies are the battery semi-active HESS and SC semi-active HESS, where the DC-DC converter is placed on the battery pack and capacitor bank respectively, $[41,43,24,49,23]$. The SC semi-active HESS enables control over the power contribution or acceptance of the SCs, and decouples the battery and SC voltage. Given independent control over the utilisation of the SCs, a larger proportion of their energy capacity can be used, and the duration of pulse power output or acceptance becomes primarily dependent upon the energy storage capacity of the SC bank. Given that the output of the SC bank can be controlled, the battery output can be kept near constant, and the DC-DC converter does not need to be active under low current or steady state conditions. Additionally, the SC bank can be sized to the energy and power requirements, and not to the system voltage requirements. It has been shown by Miller et al [25] that the optimal configuration is up-converting of a lower voltage SC bank voltage to a higher DC-bus voltage.

However, the SC semi-active HESS requires a high-power buck-boost DC-DC converter that matches the required maximum power input and output. Further, this converter must be capable of accepting a wide lower voltage range to maximize the usable energy from the SC bank, at a relatively high efficiency for the HESS to maintain acceptable levels of energy efficiency, [50]. The DC-DC converter must also have a sufficiently fast response to meet the demands of a highly transient load, [25]. A uni-directional DC-DC converter would not allow the SC bank to be used for charge acceptance, and hence would rapidly become depleted.

A battery semi-active HESS enables control of battery current, and hence the load can be kept within those limits known to reduce battery degradation. Further, the required DC-DC converter power is limited to a region between the RMS power demand and peak battery output permitted, and hence is significantly lower than in the SC semi-active HESS topology, [48].

However, a fundamental issue with the battery semi-active HESS is that the SoC of the capacitor bank controls the DC-bus voltage which becomes highly dynamic, resulting in inverter control problems, [25]. Consequently, a small SoC window must be used to maintain an acceptable voltage output. In order to provide the required energy within the SoC window the SC pack must be oversized. In addition, in this configuration the converter must be active at all times, thereby decreasing energy efficiency, [50].

\subsection{Fully-active HESS}

Many topologies exist for a fully-active HESS, [47,51,52], however discussion in this work will be limited to those in which a bi-directional converter is placed upon both the battery and the SC. This configuration enables optimal usage of both the battery pack and the SC bank, and provides the performance benefits of both the SC semi-active HESS and the battery semi-active HESS, $[48,53]$.

Whilst this system may provide the greatest control, and the best theoretical performance, it does require two DC/DC converters, one of which must be bi-directional and high power, which significantly increase the financial and package volume cost, $[45,46,50,33,54]$.

\subsection{Topology Selection}

For appropriate topology selection, it is necessary to consider the requirements of the application. The targeted application is a HEV that contains both an electrical powertrain and an internal 
combustion engine based powertrain, and therefore the primary considerations for topology selection for this application are cost, complexity, reliability and volume.

Very high power bidirectional DC-DC buck-boost converters (>60kW) with a wide input voltage range, such as those required for a SC semi-active and fully active HESS are typically large, very costly, require significant thermal management and suffer from low efficiency and reliability, $[55,56]$. Consequently, it is highly desirable to avoid the use of these devices in a HEV, thus the fully-active and SC semi-active topologies are not considered. The battery semi-active topology suffers from large DC-bus voltage fluctuations which will result in a requirement for a large input voltage range for the motor controller. Further, the fact that all energy is channelled through a DC-DC converter reduces efficiency and an oversized SC bank and DC-DC converter add cost and volume. For these reasons, a battery semi-active topology is not considered.

The passive HESS has performance benefits over a battery only system, does not substantially increase complexity and improves system reliability. Depending upon system configuration, the passive HESS can be lower in cost or mass/volume than a battery only system. Consequently, the passive HESS is the topology selected and will hereafter simply be referred to as the HESS. To the best knowledge of the author, no existing literature examines the effect of using a passive HESS in automotive traction applications.

\subsection{Experimental Setup}

\subsection{Cell Selection}

It is the intention of this study to determine whether it is possible to replace a HPB specialised for use in a HEV with a HESS consisting of SCs suitable for use in a mHEV and HEBs suitable for use in a BEV. The Saft VL6P cell is a HPB commonly used in HEV applications, [57-59], and is selected to represent a specialised cell for HEV applications and provide a baseline for comparison for the HESS.

An appropriate cell for a BEV possesses high energy-density, acceptable power density and is low cost, therefore the Panasonic 18650BD (P18650BD) cell is selected to represent the HEB. Given its successful use in the Tesla Model S, the P18650BD cell is proven to satisfy the performance requirements of a BEV, and the cost of a single cell is under \$2, [14]. The P18650BD cells are selected to determine whether an ultra low-cost system is viable. The total commercial cost of the HESS using $13 \mathrm{kF}$ cells is estimated to be $<40 \%$ of the cost of the HPB.

The loxus Titan 2000F (I2kF) SC cell is selected as the SC for use in the HESS; in addition to the characteristics required for use in a mHEV, namely high power-density, acceptable energy density and excellent cycle life, it possesses extremely low equivalent series resistance (ESR) which aids HESS performance. Where discussed, this cell was substituted with the and 3000F variant of the same cell, hereafter referred to as I3kF.

The HESS combines two series connected I2kF cells, in parallel with two parallel connected P18650BD cells, as illustrated in Figure 3a. The performance of the HESS is to be compared with that of a specialised HPB, and HEBs in parallel strings to analyse the benefits of adding SCs to an ESS consisting of a particular battery cell. The HPB has a slightly higher energy capacity than the 
batteries in the HESS (7Ah vs 6.4Ah), however the maximum cumulative energy change during the FTP drive cycle is $0.08 \mathrm{Ah}$, therefore this energy capacity difference is assumed inconsequential.

\subsection{Equating Lab Scale Test to Module Level}

In the lab-scale test a $2 \mathrm{~s} 1 \mathrm{p}$ configuration of $\mathrm{SC}$ cells was connected to a $1 \mathrm{~s} 2 \mathrm{p}$ configuration of battery cells, as per Figure $3 \mathrm{a}$, because the SC cells have a lower maximum voltage. Therefore, the ratio of SC cells to batteries in series for the lab scale test was 2:1. At a module level, this ratio would be reduced to approximately 1.4:1. For example, a $300 \mathrm{~V}$ module for a HEV must consist of approximately 69 cells in series to achieve the desired voltage, and 2 parallel strings to approximately match the energy capacity of the HPB. The maximum voltage is matched by $100 \mathrm{SC}$ cells in series (assuming the use of $3 \mathrm{~V}$ cells); the use of parallel strings of SC cells is unnecessary, as in instances where greater SC energy is required, it is best to use a larger SC cell.

At a module level the HESS will perform differently to the lab scale setup. Primarily, the relative resistance of the battery and $\mathrm{SC}$ will change, which in turn will affect the split of current between the SC and batteries. Additionally, given the smaller ratio of SC to battery cells, each SC cell will operate at a higher voltage for the $\mathrm{SC}$ bank and battery module voltage to match. The consequence of the SCs operating at a higher voltage is that they will exhibit a higher capacitance, as capacitance is a strong function of operating voltage,[60]. Therefore, smaller capacity SC cells are required in a module than in a lab scale test.

A simple function cannot be given to equate the capacitance or energy of a cell in the lab scale test to those of cells at the module level. The capacitance of the $\mathrm{SC}$ cells varies non-linearly with $\mathrm{SoC}$, and a change in energy storage of the SC cells will impact both the voltage change during operation, and the energy contribution of the battery. Determination of the equivalence of the lab-scale test to module level requires a modelling tool, which is outside of the scope of this study and the subject of further work.

\subsection{Experimental Setup}

To analyse the performance of the HESS a test rig was created to enable the measurement of HESS and battery current, cell voltages and cell temperatures, whilst controlling thermal boundary conditions and maintaining low and repeatable contact resistances. The test rig for the HESS is pictured in Figure $3 b$.

Consistent values of contact resistances are important, as the ratio of resistance between the SCS and batteries largely dictate the current split between the two devices. In order to compare the performance of the system under different conditions, it is necessary that the contact resistance does not change when cells are removed and re-connected. To maintain consistency, each time the cells were reconnected the contact areas for the cells were polished and cleaned with isopropanol to remove foreign objects, surface impurities and oxide layers, and the surface area and tightening torque of connections were controlled to consistent levels.

Thermocouples were connected to cell terminals using an electrically insulating, thermally conductive boron-nitride based epoxy, (3M TC-2810), and radially across cells using Kapton tape. Type $\mathrm{K}$ thermocouples with a precision of $0.1^{\circ} \mathrm{C}$ were used alongside a NI CompactDAQ with an NI9213 module for data acquisition. Current measurements using a hall-effect sensor were found to 
produce poor results at low battery currents, therefore shunt resistors were used for this purpose, and were placed between the SC and battery cells as shown in Figure $3 a$.

The insertion of a resistor into the circuit changes the distribution of current, however efforts were made to ensure that this effect was negligible. An oversized shunt resistor with a resistance of $1 \times 10^{-4} \Omega$ was utilised alongside a high resolution (16-bit) voltage measurement device (NI CompactDAQ with an NI9206 module); this combination yielded a resolution of $5.8 \times 10^{-2} \mathrm{~A}$ per bit. At the maximum anticipated battery operating temperature of $50^{\circ} \mathrm{C}$, the minimum resistance of each battery cell is $30 \mathrm{~m} \Omega$, reducing to $15 \mathrm{~m} \Omega$ in the $2 \mathrm{P}$ configuration; therefore the maximum reduction of battery current the $0.1 \mathrm{~m} \Omega$ shunt resistor should cause is estimated to be $0.66 \%$.

The FTP drive cycle testing was conducted using a Maccor Series 4000 battery cycler, and measurements to track degradation were completed using a Biologic BC-815 potentiostat. Data for voltage, current and temperature was acquired via a National Instruments CompactDAQ connected to the Labview software package running on a standard desktop PC.
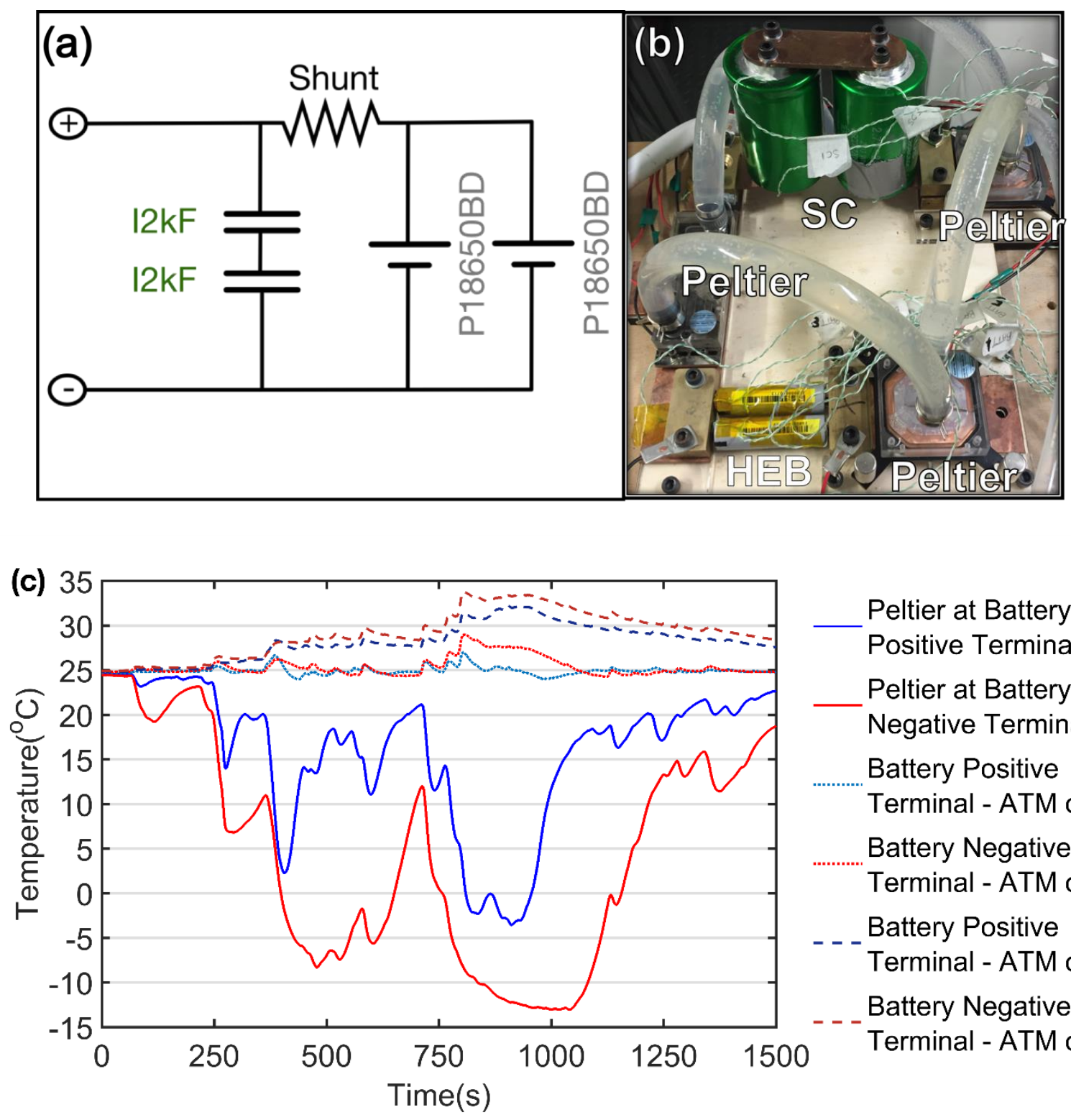

Peltier at Battery Positive Terminal Peltier at Battery Negative Terminal Battery Positive Terminal - ATM on Battery Negative Terminal - ATM on Battery Positive Terminal - ATM off Battery Negative Terminal - ATM off 
Figure 3: (a) Schematic of lab scale HESS (b) Photograph of lab scale HESS experimental setup (c) Comparative analysis of battery temperature in the HESS using I2KF SCs with and without the active thermal management system (ATM) operational

The system performance is strongly dependent on temperature; therefore, an Active Thermal Management (ATM) system is developed in order to maintain the desired test temperature, thereby largely decoupling the effect of heat generation during the test from the system performance. Peltier elements are used to cool the battery and SC terminals; the power supplies for the Peltier elements are controlled by Labview, which implements PID control to maintain either the cell or battery connector temperature at the desired level. The location of the Peltier elements is marked in Figure $3 \mathrm{~b}$; water cooling blocks placed directly atop the Peltier elements are required to maintain the cooling efficiency of the Peltier elements at acceptable levels.

The ATM system is reactive and not predictive. Whilst the temperatures do deviate from the desired level, the magnitude and duration of the deviation is greatly reduced in comparison to operation with the ATM switched off, as shown in Figure 3c. The maximum temperature rise at the negative terminal is reduced by $50 \%$, and the rise of average temperature is reduced by $90 \%$, (ATM on $25.3^{\circ} \mathrm{C}$ ATM off $-28.6^{\circ} \mathrm{C}$ ). To enable the temperature of the system to quickly return to the desired level, a high proportional gain $\left(K_{p}\right)$ value is required, however the rapidly varying rate of heat generation tends to lead to a cooling overshoot. To reduce the effect of the overshoot, the test rig is placed within a large thermal chamber which is held at the target temperature, and a series of fans is used to maintain a consistent level of forced convection, thus eliminating the need for bidirectional power supplies for the Peltier elements. The ATM has poor energy efficiency, and therefore is useful only as a lab-based tool to enable control of thermal boundary conditions to mimic those seen in a real battery pack or to enable iso-thermal operation to assist with data analysis by largely decoupling the effect of temperature.

\subsection{System Performance}

\subsection{HESS Performance Analysis}

In a HESS, the current split between the SCs and batteries is a function of time, the relative resistance of each device, and the SC capacity. Figure 4 (top) shows the battery current evolution with time as a square wave current profile is applied to the HESS. Given our lab scale experimental configuration (SC $2 s 1 p$, battery $1 \mathrm{~s} 2 \mathrm{p}$ ), the instantaneous current for each battery and SC cell can be determined by using circuit theory as:

$$
\begin{gathered}
I_{0_{\mathrm{Batt}}}=I_{\mathrm{T}}\left[1-\left(\frac{R_{\mathrm{Batt}} / n_{\mathrm{Batt}}}{\left(R_{\mathrm{SC}} \cdot n_{\mathrm{SC}}\right)+\left(\left(R_{\mathrm{Batt}}\right)^{-1} \cdot n_{\mathrm{Batt}}\right)^{-1}}\right)\right] \\
I_{0_{\mathrm{SC}}}=I_{\mathrm{T}}\left[1-\left(\frac{R_{\mathrm{SC} \cdot n_{\mathrm{SC}}}}{\left(R_{\mathrm{SC}} \cdot n_{\mathrm{SC}}\right)+\left(\left(R_{\mathrm{Batt}}\right)^{-1} \cdot n_{\mathrm{Batt}}\right)^{-1}}\right)\right]
\end{gathered}
$$

where $I_{0}(\mathrm{~A})$ is the instantaneous current at the beginning of the applied step current, $I_{\mathrm{T}}(\mathrm{A})$ the total applied current, $R(\Omega)$ the equivalent series resistance and $n$ the number of cells. The subscripts 'Batt' and 'SC' refer to the battery and SC cells respectively. 
When the HESS begins at equilibrium, the battery current approximately obeys a simple quadratic relation as a function of time during the pulse:

$$
I_{\text {Batt }}(t)=A \cdot I_{\mathrm{T}} \cdot t^{2}+B \cdot I_{\mathrm{T}} \cdot t+I_{0_{\text {Batt }}}
$$

where $A, B$ are constants fitted to experimental data, and $I_{0_{B}}$ can be calculated for $t=0$ using equation ( 1 ). Whilst the current of the system shown can be described using a linear function of time, the behaviour in HESSs using smaller SCs is best described used a quadratic function of time.
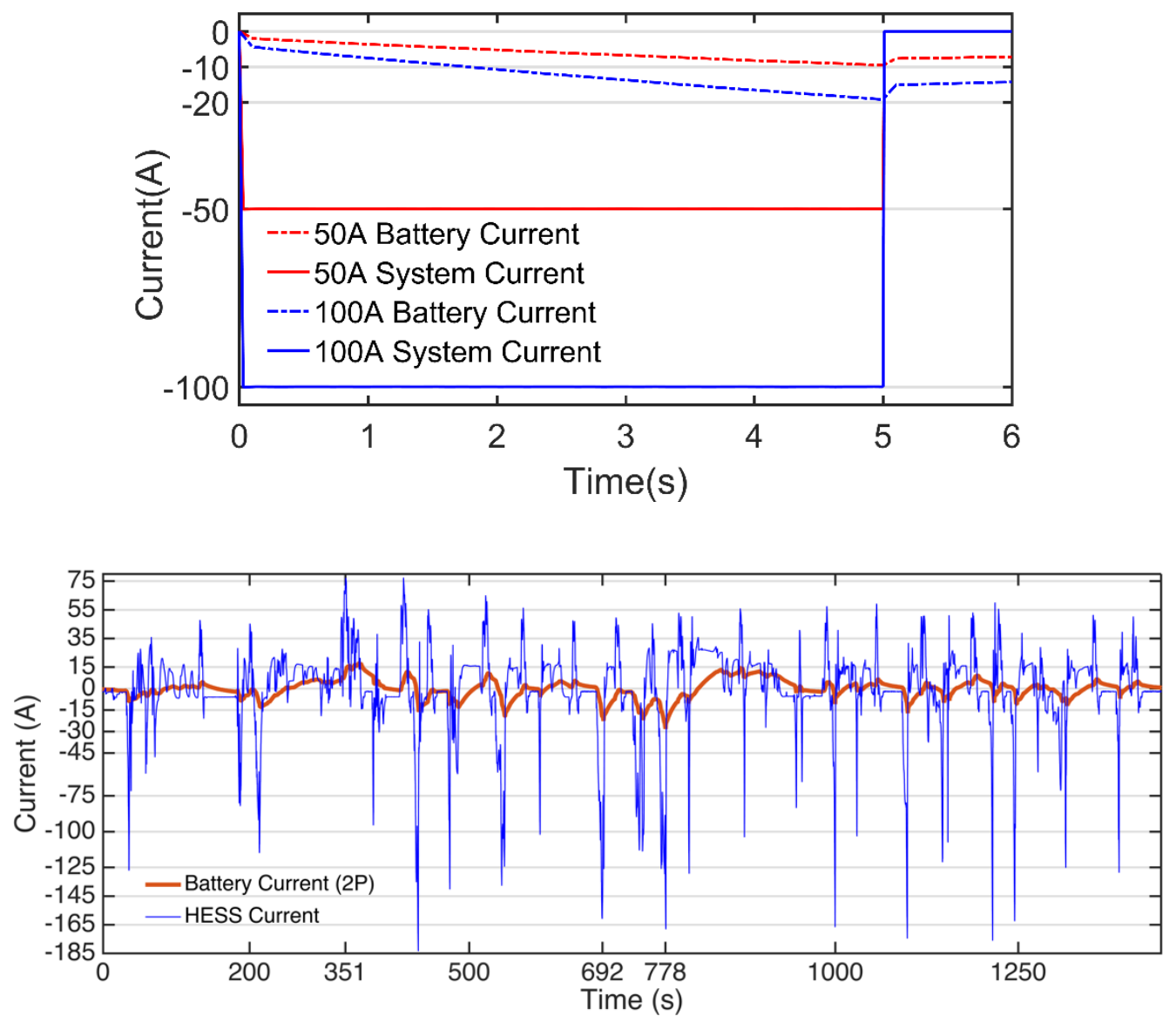

Figure 4: Comparison of HESS and battery current for 5 second square wave current pulses (top) and over the FTP drivecycle (bottom). 'Battery current' denotes the total current provided by both cells. HESS uses I3kF SCs, operated at $25^{\circ} \mathrm{C}$ with an initial voltage of $3.49 \mathrm{~V}$.

Whilst the instantaneous current split between the batteries and SCs is determined by the relative resistance of each device, the battery current increases with time during the current pulse. The greatest benefits arise when the $\mathrm{SC}$ resistance is much smaller than the battery resistance; in this configuration, the SC ESR $(0.17 \mathrm{~m} \Omega \times 2)$ is two orders of magnitude lower than the ESR of the batteries $(31.5 \mathrm{~m} \Omega / 2)$. Therefore, over a 5 second pulse $80-95 \%$ of the current is supplied by the SC. As a result, the $\mathrm{SC} \mathrm{SoC}$ and hence voltage will drop faster than the battery voltage. Given that the batteries and SC are connected in parallel in the HESS, they must remain at the same voltage. Therefore, the battery current contribution rises, simultaneously causing a decrease in the SC current contribution, until the voltage of the two devices matches. The rate of increase of battery current therefore is highly dependent upon the capacity of the SCS used in the HESS. Given an equal energy discharge, a SC of lesser capacity decreases in voltage to a greater extent as Energy = 0.5. Capacitance. Voltage ${ }^{2}$, therefore a lower capacity SC induces a higher rate of battery current 
increase during a current pulse. Following the removal of the system load, a decaying current continues to flow from the batteries to the SC until the SC voltage matches the battery voltage.

The proportion of the total current demand over the FTP drive cycle provided by the batteries is shown in Figure 4 (bottom), and the peak and RMS values are provided in Table 2. The HESS with $13 \mathrm{kF}$ capacitors decreases the peak current of the batteries by $77 \%$ during charging and by $85 \%$ during discharge, while the RMS current is reduced by $80 \%$ in comparison to the system current (which is the same as the current of the HPB).

\begin{tabular}{|c|ccc|}
\hline & \multicolumn{2}{|c|}{ Peak Current (A) } & RMS \\
& Charge & Discharge & Current (A) \\
\hline SAFT VL6P (HPB) & 77.4 & 183.5 & 28.5 \\
\hline P18650BD (HEB - 8P) & 9.6 & 23.0 & 3.73 \\
\hline HESS 2000F Battery & 10.6 & 17.8 & 3.9 \\
\hline HESS 3000F Battery & 8.9 & 14.1 & 2.8 \\
\hline
\end{tabular}

Table 2: Comparison of peak and RMS battery current over the FTP cycle at $25^{\circ} \mathrm{C}$ for each system under consideration

\subsection{HESS Performance relative to other systems}

The capability of HPBs, HEBs and HESSs to meet the current demand of the FTP drive cycle within their limits of operation is dependent upon the initial SoC, temperature, number of cells in parallel, and, in the case of the HESS, the size of the SCs. Figure 5(Top) graphically demonstrates the capability of the different types of ESSs, showing the range of SoC that can be used without compromising power capability, at different temperatures. For example, it shows that at $10^{\circ} \mathrm{C}$ an $8 \mathrm{P}$ HEB system will not work at any SOC, and at least 10 cells in parallel are required for a limited operating range at this temperature. In contrast, the 3000F HESS system with just 2 battery cells in parallel has an $\mathrm{SOC}$ window of $20-55 \%$ at $10^{\circ} \mathrm{C}$.

The cycle is charge neutral, and the maximum charge deviation during the cycle is relatively small (peak of 0.08Ah discharge) in comparison to the capacity of the battery cells tested. The limiting factor is the power capabilities of each ESS; frequent high current pulses result in failure due to the cell exceeding its safe voltage limits. The high-current pulses pose a challenge for each of the ESSs under evaluation; the presence of a current spike leads to a temporary reduction of power availability due to slow diffusion within the battery cell electrodes. This solid state diffusion limitation manifests itself as an increase in resistance. Diffusion limitations can reduce the battery power availability enough to cause sufficient increase of the battery resistance such that their voltage reaches the safety limit before meeting the requirements of the drive cycle. In a HESS, as the battery resistance rises due to diffusion limitations, an increasing current demand is placed on the SC. Consequently, the SC capacity becomes an increasingly important factor in the terminal voltage of the HESS and in determining its capabilities within safe operating limits. 

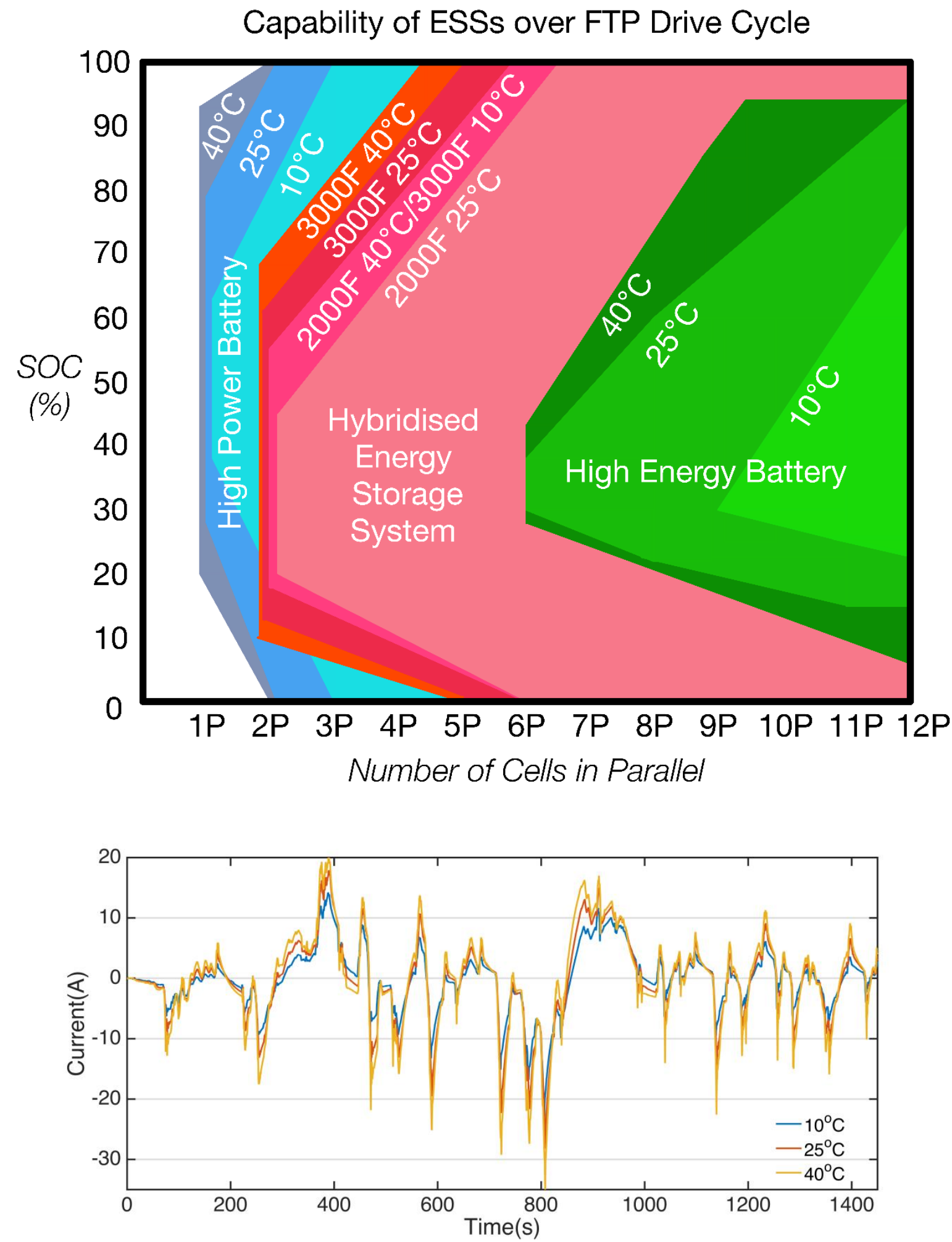

Figure 5: (Top) Experimentally determined performance map showing the ability of different energy storage systems to meet the requirements of the FTP drive cycle in a hybrid electric vehicle as a function of state of charge, number of cells in parallel, temperature, and in the case of the HESS, capacitor size. Different shades of blue show the performance of the high power battery, different shades of red show the performance of the HESS, and different shades of green show the performance of the high energy battery system. Active thermal management system is used. (Bottom) Total current provided by batteries in HESS over the FTP drive cycle at different operating temperatures 
Additionally, solid state diffusion is strongly dependent on temperature, varying according to an Arrhenius relationship; therefore, temperature strongly affects system performance. The system with the strongest temperature dependence is the HEB ESS; their thicker and denser electrodes which improve energy density simultaneously reduce diffusivity and increase the diffusion path length. In a $10 \mathrm{P}$ configuration, the window of operation for the high-energy cells is $80 \%$ smaller by capacity at $10^{\circ} \mathrm{C}$ than at $40^{\circ} \mathrm{C}$. The high-power cells show a weaker temperature dependence with a window of operation that is $66 \%$ smaller; additional details are provided in Table 3 .

\begin{tabular}{|ccccc|} 
& \multicolumn{3}{c}{ Usable SoC Range (\%) } & $\begin{array}{c}\text { Capability at } 10^{\circ} \mathrm{C} \text { relative to } \\
\mathbf{4 0} \mathbf{0}^{\circ} \mathrm{C} \text { (\%) }\end{array}$ \\
& $40^{\circ} \mathrm{C}$ & $25^{\circ} \mathrm{C}$ & $10^{\circ} \mathrm{C}$ & 34 \\
\hline SAFT VL6P (HPB - 1P) & $21-94(73)$ & $28-78(50)$ & $38-63(25)$ & 20 \\
\hline P18650BD (HEB - 10P) & $12-94(82)$ & $17-78(61)$ & $26-43(17)$ & - \\
\hline HESS 2000F (18650 - 2P) & $17-55(38)$ & $20-45(25)$ & - & 64 \\
\hline HESS 3000F (18650 - 2P) & $10-68(58)$ & $13-61(48)$ & $17-55(37)$ & \\
\hline
\end{tabular}

Table 3: Experimentally determined effect of temperature on usable SoC range to run the FTP drive - values in brackets show difference between minimum and maximum SoC

The HESS shows a weaker dependence upon temperature, with the system using I3kF capacitors exhibiting a usable $\mathrm{SoC}$ range that is $36 \%$ smaller by capacity at $10^{\circ} \mathrm{C}$ than at $40^{\circ} \mathrm{C}$. At lower temperatures battery resistance increases significantly, whereas the $\mathrm{SC}$ resistance remains relatively constant, [60]. Consequently, the ratio of the relative resistance of the battery to the SCs increases, leading to a reduction of the battery current contribution to system current. The effect is significant, as the battery current is reduced by up to $55 \%$ when operated at $10^{\circ} \mathrm{C}$ compared with $40^{\circ} \mathrm{C}$ as shown in Figure 5 (bottom). Therefore, in the HESS the reduced power capability of the battery cells at low temperatures is offset by a significantly reduced battery current demand.

The battery current demand might appear similar for the HEB system and the HESS using 2000F SCs, (similar RMS and peak values of current, shown in Table 2), however the current varies considerably when considered in the time domain. Figure 6a shows a comparison of the battery current over the FTP drive cycle for the HEB, HESS 2000F and HESS 3000F. The profile of the current demand for the HEB system is a downscaled version of the FTP-72 drive cycle, however in the HESS the SCS smoothen this load considerably, reducing the rate of current change. The histograms in Figure $6 \mathrm{~b}$ show that the HEB system demands a wide range of battery currents with appreciable time spent above 10A. Comparatively, the HESS spends significantly less time providing a current of over 10A, and a greater period of time providing less than 10A. As the batteries in the HEB ESS and the HESS are utilised in a very different manner, the factors limiting performance differ.

The capability of the HEB system is limited by its power capability, and as discussed previously, the power availability is particularly poor when the HEB cell is not at equilibrium due to diffusion limitations. The HEB system is sized by adjusting the number of cells in parallel to reduce current demand to a level where each cell has sufficient power available to meet the requirements.

The capability of the HESS is limited by SC capacity and battery power availability, which are coupled, and by the SC ESR. Battery resistance increases as power availability is reduced, thus battery power availability impacts the current demand placed upon the SCs as the ratio of battery to SC resistance 
changes, resulting in a change in rate of $\mathrm{SC}$ SoC variation. Following the removal of a load, current transfer occurs between the $\mathrm{SC}$ and battery at a decaying rate as necessary to maintain the two devices at an equal voltage. Thus, the greater the change of SC SoC, the greater the power demand on the battery, and thus the lower the battery power availability shortly after a charge/discharge event. A SC of greater capacity reduces SC SoC variations, improves battery power availability and reduces battery Energy Throughput (ET).
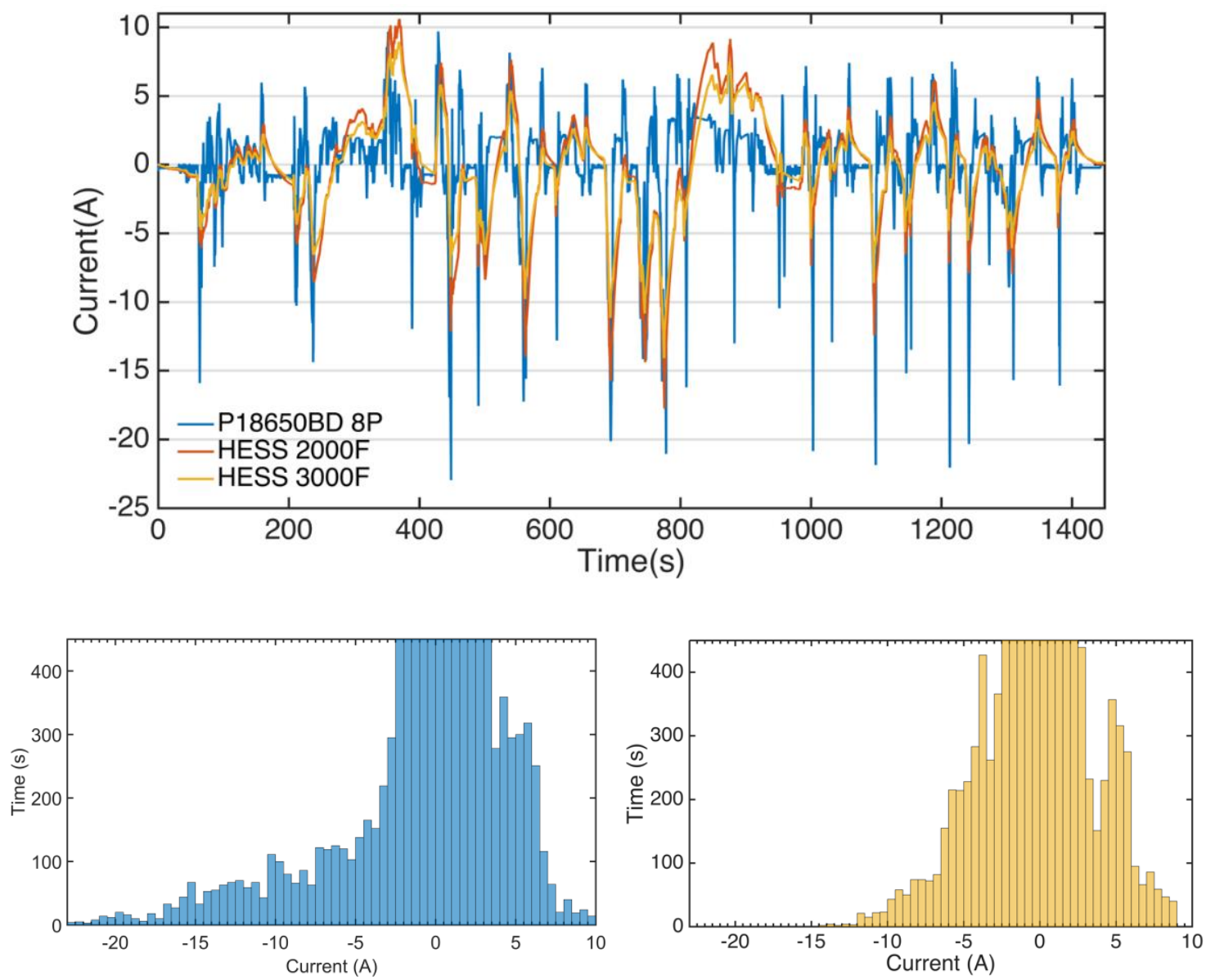

Figure 6: (a) Battery current comparison between HESS using 2000F and 3000F Capacitors and high-energy cells in 8P configuration - Initial Conditions: $3.49 \mathrm{~V}, 25^{\circ} \mathrm{C}$, ATM on (b) Histograms showing the current distribution from a single battery within the HEB ESS in the 8P configuration (left) and a single battery in the I3kF HESS (right)

The voltage change of the HESS mirrors the behaviour of the battery current; the voltage change during the FTP drive cycle is significantly greater (up to 60\%) with the I2kF SCs than with the I3kF SCs. This is attributable to the increased demand placed upon the battery in the HESS using I2kF SCS due to the lower SC capacitance and higher SC resistance.

It is necessary to consider heat generation alongside temperature change to compare thermal management requirements. In high current, pulse load applications, heat generation is dominated by electrical losses, $[61,62]$, therefore other sources can be neglected, entropy, species transport, degradation inducing reactions, [63]). The electrical losses are the combined losses attributable to interfacial kinetics and ohmic losses and can be determined using the over-potential as per equation 4 , where $I$ is the applied current (A), R is the resistance $(\Omega)$ and the over-potential can be defined as $\eta=\left|V_{\text {terminal }}-V_{O C V}\right|$. The cumulative heat generation for each ESS over the FTP drive cycle is presented in Table 4, and the measured cell temperature is shown in Figure 7. 


$$
\dot{Q}_{E l \_L o s s}(t)=I^{2} R(t)=I \eta(t)
$$

\begin{tabular}{|c|c|c|c|c|}
\hline & Battery Heat (J) & SC Heat (J) & $\begin{array}{c}\text { Module Configuration } \\
\text { Battery | SC }\end{array}$ & $\begin{array}{c}\text { HV Module Heat } \\
\text { (J) }\end{array}$ \\
\hline HPB & 2549 & - & 72 S1P & 183,528 \\
\hline HEB & 801 & - & $69 S 8 P$ & 442,152 \\
\hline HESS 2000F & 1372 & 171 & $69 S 2 P \mid 100 S 1 P$ & 206,453 \\
\hline HESS 3000F & 906 & 158 & $69 S 2 P \mid 100 S 1 P$ & 140,828 \\
\hline
\end{tabular}

Table 4: Cumulative heat generation for each ESS over the FTP drive cycle - Initial Conditions: HESS and HEB systems at $3.49 \mathrm{~V}$ and $\mathrm{HPB}$ at $3.57 \mathrm{~V}$ (corresponding to midpoint of usable $\mathrm{SoC}$ at $10^{\circ} \mathrm{C}$ ), both systems at $25^{\circ} \mathrm{C}$

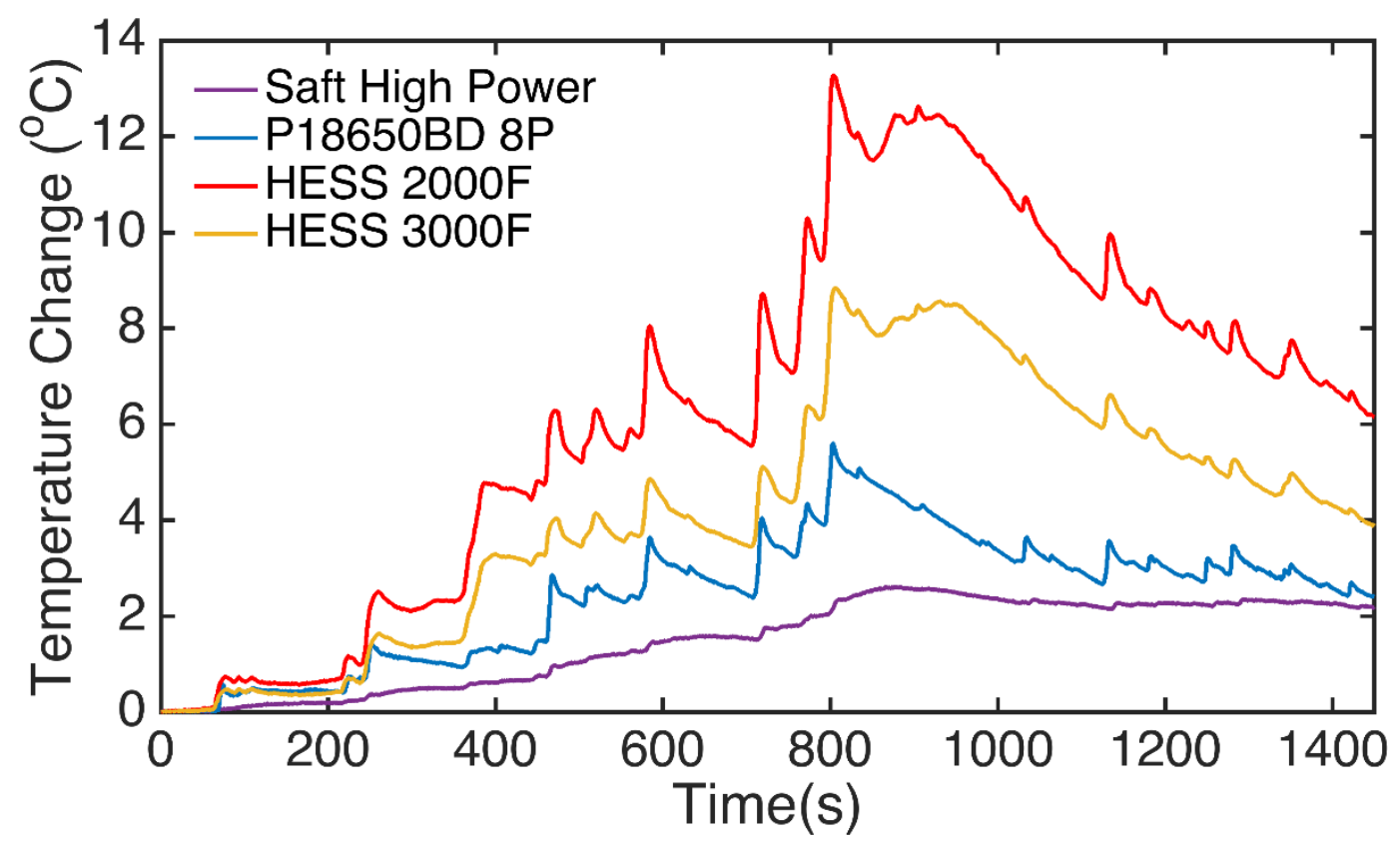

Figure 7: Battery temperatures at the negative terminal - Initial Conditions: HESS and HEB systems at 3.49V and HPB at $3.57 \mathrm{~V}$ (corresponding to midpoint of usable $\mathrm{SoC}$ at $10^{\circ} \mathrm{C}$ ), both systems at $25^{\circ} \mathrm{C}$

When each system is tested with the ATM system switched off, the HPB experiences the smallest temperature increase, whilst the batteries in the HESS using 2000F SCs experience the largest. Although the HPB generates the greatest amount of heat at the cell level, it increases in temperature the least as the cell has a significantly greater thermal mass than the HEB used. The batteries in the HESS using 2000F SCs increase in temperature the most; their ET (as presented in Table 5) and therefore heat generation is greater than the other ESSs using the HEB cell. The temperature rise at the terminals of the SCs did not exceed $1^{\circ} \mathrm{C}$ for either HESS, and the vast majority of heat generation occurs within the battery cells.

Whilst the cell level temperature rise is greatest in the HESS battery cells, at the module level the heat generated by the HESSs is significantly less than the HEB system, and comparable to the HPB system. The $2000 \mathrm{~F}$ HESS configuration generates $12 \%$ more heat than the HPB ESS, whilst the 3000F system generates $23 \%$ less heat. It can therefore be concluded that an appropriately sized HESS will generate less heat than a HPB ESS, the bulk of the heat generation occurs within the battery cells and therefore is more localised, and passive thermal management should suffice for the SCs. A 
reduction of heat generated and increased localisation should enable thermal management system downsizing and reduced thermal losses demonstrate improved energy efficiency.

\begin{tabular}{|l|cc|}
\hline & $\begin{array}{c}\text { Energy Throughput per Cycle (kJ) } \\
\text { HPB System }\end{array}$ & $\begin{array}{c}\text { Reduction of battery energy } \\
\text { throughput (\%) }\end{array}$ \\
\hline HEB System & 86.0 & - \\
\hline HEB Single Cell & 85.6 & - \\
\hline HESS 2000F System & 10.7 & 88 \\
\hline HESS 2000F Each HEB Cell & 86.2 & 83 \\
\hline HESS 3000F System & 14.8 & - \\
\hline HESS 3000F Each HEB Cell & 86.8 & 87 \\
\hline
\end{tabular}

Table 5: Energy throughput for each ESS during the FTP drive cycle - Initial Conditions: HESS and HEB systems at 3.49V and $\mathrm{HPB}$ at $3.57 \mathrm{~V}$, temperature of $25^{\circ} \mathrm{C}$ with active thermal management system enabled. (* calculated with respect to the ET of each system)

\subsection{System Specification}

Whilst it has been shown that the HESS can perform comparably to the specialised HPB from the perspective of meeting the power demand of a certification drive-cycle, it is necessary to consider the additional factors important in system design. The cost, mass and volume of the ESS are key considerations in the adoption of HESSs in hybridised vehicles, as both an electrified and an internal combustion engine must be integrated into a single vehicle powertrain. The battery cells used in both tested HESSs were selected because they were highly advantageous from a cost perspective, however the high resistance of the battery cells requires large capacity SC cells. Consequently, the trade-off for low cost in this case is a significant increase in both mass and volume, as shown in Table 6. In the context of an executive saloon vehicle, such as a BMW 3 Series or Audi A4, implementation of the $3000 \mathrm{~F}$ HESS would save $\mathrm{f398}$ in cell cost per vehicle, however would require the sacrifice of $6 \%$ of the boot volume.

The cost of converting cells to modules is expected to be similar for both battery-only ESSs and HESSs; the HESS may enable slight thermal management system downsizing (depending upon system sizing), and the cost of additional sensors and a capacitor management system is expected to be small. As discussed in section 4.2, it should be noted that smaller capacity SCs can be used in a module than in the lab scale test. Additionally, it is not practical to implement the HEB ESS shown in Table 6 primarily due to its poor performance at low temperatures.

\begin{tabular}{|l|l|l|l|l|}
\hline & HPB & HEB (8P) & HESS 2000F & HESS 3000F \\
\hline Mass (Kg) & 24.9 & 25.0 & 36.3 & 54.6 \\
\hline Volume (L) & 12.8 & 10.7 & 30.7 & 41.8 \\
\hline Energy (kWh) & 1.68 & 6.45 & $1.61^{1}$ & $1.61^{1}$ \\
\hline Usable Energy (kWh) ${ }^{2}$ & 0.87 & 2.13 & 0.40 & 0.79 \\
\hline Cell Cost / Module (E) & 1584 & 813 & 1063 & 1186
\end{tabular}

${ }^{1}$ Battery Energy Only, ${ }^{2}$ Within SoC region where FTP cycle can be run

Table 6: Specification of modules consisting of HPB, HEB and HESSs using 2000F and 3000F SCs - Usable energy capacity at $25^{\circ} \mathrm{C}$

Customers demand greater EV driving range from second generation HEVs, thus it would follow that a large form factor battery cell (as is the trend with EV battery selection) would be used in a HESS. In 
a HESS with a large form factor battery, a significantly smaller SC cell could be used owing to the lower battery ESR and high power capability. Cost, performance and weight/volume can be traded off against one another by using different cell types and configurations to create a HESS with the desired attributes. ${ }^{1}$ Battery Energy Only, ${ }^{2}$ Within assumed SoC region where FTP cycle can be run

Table 7 shows potential systems using large form factor battery cells with a target of $>4.5 \mathrm{kWh}$ of usable energy. Based on the results of this study, it is predicted that a HESS consisting of large form factor battery cells and ultra-low resistance 600F SC cells provides performance that is competitive with the HPB ESS. This configuration was selected to demonstrate that for particular requirements, a HESS could provide a lighter and cheaper ESS than a battery only ESS.

\begin{tabular}{|l|l|l|l|l|}
\hline & HPB & HEB & HESS 2000F & HESS - 600F \\
\hline Configuration & $\begin{array}{l}72 S \text { 3P } \\
\text { (Saft VL6P) }\end{array}$ & $\begin{array}{l}\text { 69S 2P } \\
\text { (EIG 20Ah) }\end{array}$ & $\begin{array}{l}\text { 69S 1P (EIG 20Ah) } \\
\text { \& 96S 1P (I2kF SC) }\end{array}$ & $\begin{array}{l}\text { 69S 1P (EIG 20Ah) \& } \\
\text { 96S 1P (600F Low ESR } \\
\text { SC) }\end{array}$ \\
\hline Mass (Kg) & 74.5 & 62.1 & 59.8 & 53.1 \\
\hline Volume (L) & 38.2 & 59.0 & 59.3 & 41.8 \\
\hline Energy (kWh) & 5.0 & 10.6 & $5.3^{1}$ & $5.3^{1}$ \\
\hline $\begin{array}{l}\text { Usable Energy } \\
\text { (kWh) }\end{array}$ & 4.8 & 3.7 & 4.8 & 4.5 \\
\hline $\begin{array}{l}\text { Cell Cost / } \\
\text { Module (E) }\end{array}$ & 4752 & 3179 & 2450 & 2142 \\
\hline
\end{tabular}

${ }^{1}$ Battery Energy Only, ${ }^{2}$ Within assumed SoC region where FTP cycle can be run

Table 7: Specification of modules consisting of HPB, HEB and HESSs using 2000F and 3000F SCs for higher energy capacity $\mathrm{HEV}$ s - Usable energy capacity at $25^{\circ} \mathrm{C}$

\subsection{Degradation}

To evaluate the hypothesis that the HESS degrades at a similar rate to a specialised HPB, tests were conducted to determine the capacity loss and resistance rise following prolonged usage under typical automotive conditions. The FTP-72 drive cycle was run continuously for 1080 cycles, with degradation measured periodically via a $\mathrm{C} / 20$ discharge, a pulse discharge, Electrochemical Impedance Spectroscopy (EIS), and a high-rate discharge. All measurements were performed at $25^{\circ} \mathrm{C}$, with forced convection but without active thermal management.

For each ESS, the thermal boundary conditions were controlled to mimic tab cooling at module level; the cells were subjected to forced convection in a temperature controlled environment, and the connections to the battery tabs and SC terminals were held at a constant temperature of $25^{\circ} \mathrm{C}$. The initial SoC used for each ESS was the mid-point of the usable SoC range in which the FTP-72 cycle would run. Following each cycle, the cell was charged using a constant-voltage regime to the voltage corresponding to the initial SoC for a period of two minutes to prevent voltage drift during cycling.

In the following analysis the data provided for the HESS system is that describing the battery cells in a 3000F HESS, as SC degradation was found to be negligible. Additionally, all analysis should be considered qualitative rather than quantitative, as it was not performed on a statistically significant number of samples. 


\begin{tabular}{|l|lll|l|l|}
\hline Cell & $\begin{array}{l}\text { Capacity } \\
\text { (mAh) 0 } \\
\text { Cycles }\end{array}$ & $\begin{array}{l}\text { Capacity } \\
\text { (mAh) 528 } \\
\text { Cycles }\end{array}$ & $\begin{array}{l}\text { Capacity } \\
\text { (mAh) 1080 } \\
\text { Cycles }\end{array}$ & $\begin{array}{l}\text { Capacity Loss } \\
\text { (mAh) }\end{array}$ & $\begin{array}{l}\text { Normalised } \\
\text { Loss (\%) }\end{array}$ \\
\hline HPB & 7660 & 7571 & 7410 & 250 & $3.3 \%$ \\
\hline HEB (8P) & 3020 & 2997 & 2970 & 50 & $1.7 \%$ \\
\hline HESS Cell 1 & 3005 & 2897 & 2874 & 131 & $4.3 \%$ \\
\hline HESS Cell 2 & 2963 & 2907 & 2884 & 79 & $2.7 \%$ \\
\hline
\end{tabular}

Table 8: Capacity loss during degradation testing determined via a C/20 discharge

Table 8 shows the capacity loss of batteries in each ESS during degradation testing; in each case, the capacity loss after 1080 runs of the FTP-72 cycle is modest. The capacity loss of the HPB is similar to the average between HESS losses (3.3\% vs $3.6 \%$ ) indicating that the HESS has a similar rate of degradation to the specialised HPB. As expected, the lowest capacity loss is seen in the HEB in the 8P configuration. Since the system is oversized to meet the pulse power requirements, the ET for a single cell was lower than that for a cell in the HESS.

\begin{tabular}{|c|c|c|c|c|c|c|}
\hline Cell & $\begin{array}{c}\text { Series } \\
\text { Resistance }\end{array}$ & $\begin{array}{l}\text { Fitting } \\
\text { Error (\%) }\end{array}$ & $\begin{array}{c}\text { SEI } \\
\text { Resistance }\end{array}$ & $\begin{array}{c}\text { Fitting } \\
\text { Error (\%) }\end{array}$ & $\begin{array}{c}\text { Charge } \\
\text { Transfer } \\
\text { Resistance }\end{array}$ & $\begin{array}{l}\text { Fitting } \\
\text { Error (\%) }\end{array}$ \\
\hline \multicolumn{7}{|l|}{ HPB } \\
\hline New & 0.00064 & 6.0 & 0.00257 & 3.9 & 0.0017 & 4.4 \\
\hline Aged & 0.00066 & 7.0 & 0.00253 & 3.9 & 0.0020 & 1.1 \\
\hline Increase (\%) & $3.1 \%$ & & $-1.8 \%$ & & $15.5 \%$ & \\
\hline \multicolumn{7}{|l|}{ HEB (8P) } \\
\hline New & 0.0239 & 1.0 & 0.00751 & 4.5 & 0.0191 & 3.9 \\
\hline Aged & 0.0241 & 1.2 & 0.00780 & 3.1 & 0.0208 & 3.1 \\
\hline Increase (\%) & $0.0 \%$ & & $3.8 \%$ & & $8.5 \%$ & \\
\hline \multicolumn{7}{|l|}{ HESS Cell 1} \\
\hline New & 0.0263 & $0.4 \%$ & 0.00407 & $3.4 \%$ & 0.0221 & $1.5 \%$ \\
\hline Aged & 0.0279 & $0.3 \%$ & 0.00512 & $2.6 \%$ & 0.0239 & $2.0 \%$ \\
\hline Increase (\%) & $6.1 \%$ & & $25.9 \%$ & & $8.3 \%$ & \\
\hline \multicolumn{7}{|l|}{ HESS Cell 2} \\
\hline New & 0.0259 & $0.48 \%$ & 0.00419 & $5.99 \%$ & 0.0219 & $2.10 \%$ \\
\hline Aged & 0.0276 & $0.33 \%$ & 0.00499 & $2.59 \%$ & 0.0236 & $1.96 \%$ \\
\hline Increase (\%) & $6.9 \%$ & & $19.1 \%$ & & $7.2 \%$ & \\
\hline
\end{tabular}

Table 9: Series, SEI and Charge Transfer Resistance of new and aged cells, as determined through EIS - EIS plots shown in Figure 8

In order to distinguish different forms of degradation, the series, SEI and Charge Transfer Resistances (CTR) have been extracted from EIS measurements. The resistance values are listed in Table 9 and the equivalent circuit used for fitting is shown in Figure 8 (Top).

In the HPB the largest increase (of 15\%) is that of the charge transfer resistance; the variations of series and SEI resistances are within fitting error. Given the presence of a significant capacity loss and limited changes in series and SEI resistances, it is hypothesised that the main degradation mechanism is structural disordering, [64]. Lithium ions replace divalent Nickel atoms within the cathode, resulting in a consumption of lithium from the electrolyte, and the modified structure 
restricts lithium diffusion within the cathode; these lead to capacity fade and charge transfer resistance rise.

The HEB in the $8 \mathrm{P}$ configuration experiences little change in its series and SEI resistance, and a modest increase in CTR. In comparison, the battery cells in the HESS show a similar increase in CTR, but significantly greater rise of SEI and series resistances. This effect is expected, given that the average temperature of the cells is greater in the HESS than in the HEB system, causing faster reaction kinetics, and SEI growth.

EIS spectra of the new and aged cells from the HESS are shown in Figure 8 (Top). In the 'new' state, the cells show similar impedance spectra, with modest but notable differences. The greater depression of the first semi-circle for Cell 2 indicates a greater SEI resistance than Cell 1, additionally, there is notable difference in the radius of the second semi-circle which indicates a change of charge transfer resistance, [65]. It is clear however that, with the exception of series resistance, the spectra of both cells in the aged state are almost identical. As the cells aged, the parallel connection of the battery cells served to self-balance cell state-of-health and thus led to a convergence of the two EIS spectra. 

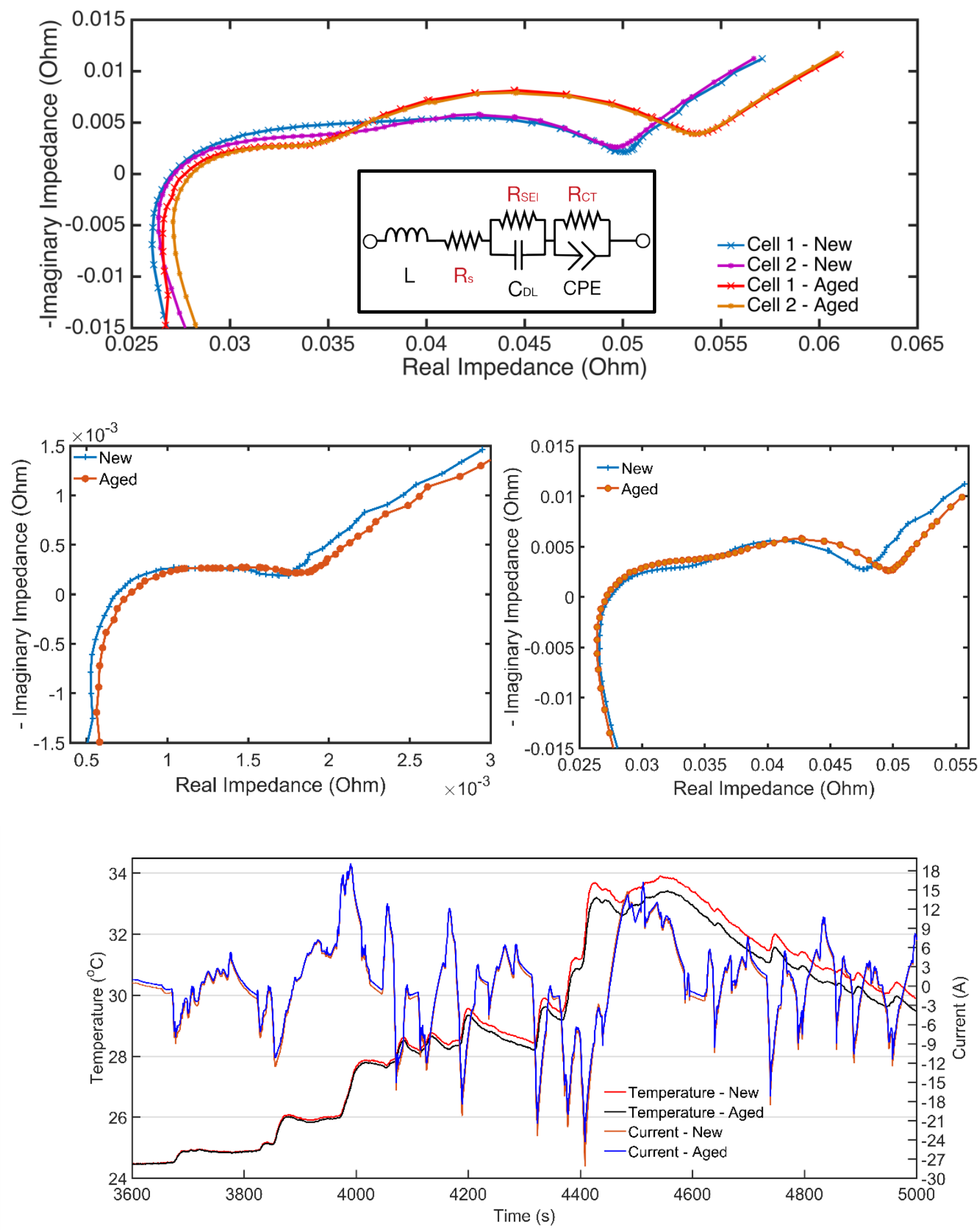

Figure 8: Comparison of new and aged cells through EIS: EIS Plots (Top) of HESS (inset shows the equivalent circuit to which data was fitted), (Mid-Left) HPB, (Mid-Right) HEB, (Bottom) Temperature and current over the FTP drive cycle at various stages of cell aging

As the battery cells degrade and their resistance increases, a greater proportion of the system resistance is attributable to the batteries, and hence the SCs provide a larger contribution to the total system current. As shown in Figure 8 (Bottom), the reduction in current provided by the batteries leads to a reduction in the temperature rise of the cells. This suggests that the thermal management system for the batteries in a HESS should be sized for start of life, and not end of life as 
per convention in systems with battery cells only. Furthermore, this effect should act to balance parallel strings in the battery pack, where lower resistance cells provide more power and naturally reduce the duty on the more degraded cells.

\subsection{Conclusions}

An investigation is carried out to determine whether High Energy Batteries (HEBs) suitable for use in a Battery Electric Vehicle (BEV) can be combined with Supercapacitors (SCs) in a Hybridised Energy Storage System (HESS) in order to replace a specialised High Power Battery (HPB) in a Hybrid Electric Vehicle (HEV). Multiple system topologies are evaluated which can be broadly categorised as passive, semi-active and fully-active, and a passive configuration, in which SCs are connected in parallel with $\mathrm{HEBs}$, is preferred from cost and reliability perspective.

The electrical and thermal performance of the HESS is evaluated over an automotive drive cycle (FTP-72), using the current demand for a HEV, with appropriate thermal boundary conditions for the application. The SoC range over which the HESS is capable of satisfying the current demand is very similar to the specialised $\mathrm{HPB}$ at $25^{\circ} \mathrm{C}$, (SoC Range of $48 \%$ vs $50 \%$ ), and similar performance using HEBs would require the use of a 10P configuration. A considerable variation is found between the temperature sensitivities of the Energy Storage Systems (ESSs) considered; in comparison to system performance at $40^{\circ} \mathrm{C}$, at $10^{\circ} \mathrm{C}$ the SoC region of operation is reduced by $80 \%$ for the HEB ESS, $66 \%$ for the HPB ESS, and $36 \%$ for the HESS. The performance is reduced at lower temperatures due to increased battery resistance, however in the HESS, this is partially offset by an increased SC contribution to the system energy throughput.

Of the ESSs considered, perhaps counterintuitively, the battery cells in the HESS experience the greatest temperature rise. Whilst the energy throughput of each battery cell in the HESS is reduced by over $80 \%$ with respect to the energy throughput of the HPB, the energy throughput of each cell is greater (by 11-38\% depending on SC size) than through a HEB in an $8 \mathrm{P}$ configuration, thus more heat is generated. However, when considering heat generation at a module level, significantly less heat is generated by the 3000F HESS than both the HEB and HPB ESSs, enabling downsizing of the thermal management system. Reduced thermal losses indicate that a correctly sized HESS is more efficient than a HPB ESS.

Degradation testing of the specialised HPB and the HESS is performed by running the FTP-72 drive cycle 1080 times. The SCs in these systems do not degrade significantly. The capacity loss of the HPB and HEBs in the HESS is similar (3.3 vs 3.6\%). All ESSs tested experience a statistically significant increase in charge transfer resistance, while the batteries in the HESS also experience a rise in series and SEI resistances. It is hypothesised that the main contributor to the rise in charge transfer resistance is structural disordering of the cathode. Given the higher temperature in the HESS cells during degradation testing, it is hypothesised that the notable series and SEI resistance increase in the HESS cells is a result of increased electrolyte decomposition and subsequent growth of the SEI layer.

As the batteries in the HESS degrade, their resistance increases while that of the SCs does not vary; as a result, the SC current contribution increases, resulting in a reduction of battery current. The temperature rise within the batteries is reduced, meaning the thermal management system for a 
HESS should be sized for beginning of life rather than end of life, as is the case for battery-only systems. Additionally, it is hypothesised that the rate of battery degradation in the HESS will continue to decrease as battery current demand drops.

The combination of battery cells and supercapacitors in a passive system was shown to be a promising solution for the very power demanding HEV. Based on the analysis presented here, further optimisation of this system can be performed to suit the particular application of interest.

\section{Acknowledgements}

The authors gratefully acknowledge funding and support provided by Jaguar Land Rover and the Innovate UK's Knowledge Transfer Partnership scheme award number KTP9095, and the EPSRC for funding of this work through a Career Acceleration Fellowship for Gregory Offer, award number $\mathrm{EP} / 100422 \mathrm{X} / 1$.

\section{References}

[1] USABC, USABC Goals for Advanced Batteries for 48V Hybrid Electric Vehicle Applications USABC Requirements of Energy Storage Systems for 48V HEV's at EOL, 2014.

[2] U.D. of Energy, U .S. Department of Energy Vehicle Technologies Program Battery Test Manual For Plug-In Hybrid Electric Vehicles, 2014.

[3] D. Kok, S. Chorian, Designing The Right Battery For The Right Vehicle, in: AABC 2015, 2015.

[4] R. Matthe, Oem perspective on battery support for lifetime: repair refurbishment re-use recycle, AABC 2015. (2015).

[5] A. Oury, 2016 CHEVROLET MALIBU HYBRID BATTERY PACK, in: AABC 2015, 2016.

[6] USABC, USABC Goals for Advanced Batteries for PHEVs for FY 2018 to 2020 Commercialization, 2014.

[7] USCAR, USCAR: Energy Storage System Goals, 2015. http://www.uscar.org/guest/article_view.php?articles_id=85.

[8] W. Zhou, Thermal Design and Simulation of Traction Batteries in Vehicles, in: AABC Eur. 2015, 2015: pp. 1-18.

[9] T. Glass, Lithium-Ion Battery Audi Q7 e-tron, in: AABC 2016, 2016: pp. 1-15.

[10] M. Schneider, Li-lon battery for 48V application, in: AABC 2016, 2016.

[11] E. Karden, P. Shinn, P. Bostock, J. Cunningham, E. Schoultz, D. Kok, Requirements for future automotive batteries - a snapshot, J. Power Sources. 144 (2005) 505-512. doi:10.1016/j.jpowsour.2004.11.007.

[12] E. Karden, S. Ploumen, B. Fricke, T. Miller, K. Snyder, Energy storage devices for future hybrid electric vehicles, J. Power Sources. 168 (2007) 2-11. doi:10.1016/j.jpowsour.2006.10.090.

[13] S. Amjad, S. Neelakrishnan, R. Rudramoorthy, Review of design considerations and technological challenges for successful development and deployment of plug-in hybrid electric vehicles, Renew. Sustain. Energy Rev. 14 (2010) 1104-1110. 
doi:10.1016/j.rser.2009.11.001.

[14] M. Anderman, Tesla Motors, the Gigafactory, and their impact on the xEV Industry, in: AABC 2015, 2015.

[15] A.W. Stienecker, T. Stuart, C. Ashtiani, An ultracapacitor circuit for reducing sulfation in lead acid batteries for Mild Hybrid Electric Vehicles, J. Power Sources. 156 (2006) 755-762. doi:10.1016/j.jpowsour.2005.06.014.

[16] J.N. Marie-Francoise, H. Gualous, R. Outbib, A. Berthon, 42V Power Net with supercapacitor and battery for automotive applications, J. Power Sources. 143 (2005) 275-283.

doi:10.1016/j.jpowsour.2004.12.011.

[17] J. Bauman, M. Kazerani, A Comparative Study of Fuel-Cell-Battery, Fuel-Cell-Ultracapacitor, and Fuel-Cell-Battery-Ultracapacitor Vehicles, IEEE Trans. Veh. Technol. 57 (2008) 760-769. doi:10.1109/TVT.2007.906379.

[18] C. Ashtiani, R. Wright, G. Hunt, Ultracapacitors for automotive applications, 2006. doi:10.1016/j.jpowsour.2005.10.082.

[19] J. Jian Cao, A. Emadi, A New Battery/UltraCapacitor Hybrid Energy Storage System for Electric, Hybrid, and Plug-In Hybrid Electric Vehicles, IEEE Trans. Power Electron. 27 (2012) 122-132. doi:10.1109/TPEL.2011.2151206.

[20] F.S. Garcia, A.A. Ferreira, J.A. Pomilio, Control Strategy for Battery-Ultracapacitor Hybrid Energy Storage System, in: 2009 Twenty-Fourth Annu. IEEE Appl. Power Electron. Conf. Expo., IEEE, 2009: pp. 826-832. doi:10.1109/APEC.2009.4802757.

[21] A. Khaligh, Z. Zhihao Li, Battery, Ultracapacitor, Fuel Cell, and Hybrid Energy Storage Systems for Electric, Hybrid Electric, Fuel Cell, and Plug-In Hybrid Electric Vehicles: State of the Art, IEEE Trans. Veh. Technol. 59 (2010) 2806-2814. doi:10.1109/TVT.2010.2047877.

[22] A.C. Baisden, A. Emadi, ADVISOR-Based Model of a Battery and an Ultra-Capacitor Energy Source for Hybrid Electric Vehicles, IEEE Trans. Veh. Technol. 53 (2004) 199-205. doi:10.1109/TVT.2003.822004.

[23] J. Park, B. Raju, A. Emadi, Effects of an Ultra-Capacitor and Battery Energy Storage System in a Hybrid Electric Vehicle, (2012).

[24] A. Kuperman, I. Aharon, S. Malki, A. Kara, Design of a Semiactive Battery-Ultracapacitor Hybrid Energy Source, IEEE Trans. Power Electron. 28 (2013) 806-815.

doi:10.1109/TPEL.2012.2203361.

[25] J.M. Miller, G. Sartorelli, Battery and ultracapacitor combinations - Where should the converter go?, in: 2010 IEEE Veh. Power Propuls. Conf., IEEE, 2010: pp. 1-7. doi:10.1109/VPPC.2010.5729216.

[26] R.A. Dougal, S. Liu, R.E. White, Power and life extension of battery-ultracapacitor hybrids, IEEE Trans. Components Packag. Technol. 25 (2002) 120-131. doi:10.1109/6144.991184.

[27] H.A. Catherino, J.F. Burgel, P.L. Shi, A. Rusek, X. Zou, Hybrid power supplies: A capacitorassisted battery, J. Power Sources. 162 (2006) 965-970. doi:10.1016/j.jpowsour.2005.07.012.

[28] D. Shin, Y. Kim, Y. Wang, N. Chang, M. Pedram, Constant-current regulator-based batterysupercapacitor hybrid architecture for high-rate pulsed load applications, J. Power Sources. 
205 (2012) 516-524. doi:10.1016/j.jpowsour.2011.12.043.

[29] C.G. Hochgraf, J.K. Basco, T.P. Bohn, I. Bloom, Effect of ultracapacitor-modified PHEV protocol on performance degradation in lithium-ion cells, J. Power Sources. 246 (2014) 965-969. doi:10.1016/j.jpowsour.2012.09.038.

[30] S. Pay, Y. Baghzouz, Effectiveness of battery-supercapacitor combination in electric vehicles, in: 2003 IEEE Bol. Power Tech Conf. Proceedings, IEEE, 2003: pp. 728-733. doi:10.1109/PTC.2003.1304472.

[31] R. Carter, A. Cruden, P.J. Hall, Optimizing for Efficiency or Battery Life in a Battery/Supercapacitor Electric Vehicle, IEEE Trans. Veh. Technol. 61 (2012) 1526-1533. doi:10.1109/TVT.2012.2188551.

[32] D. Hoelscher, A. Skorcz, Y. Gao, M. Ehsani, Hybridized Electric Energy Storage Systems for Hybrid Electric Vehicles, in: 2006 IEEE Veh. Power Propuls. Conf., IEEE, 2006: pp. 1-6. doi:10.1109/VPPC.2006.364302.

[33] H. Farzanehfard, D.S. Beyragh, E. Adib, A bidirectional soft switched ultracapacitor interface circuit for hybrid electric vehicles, Energy Convers. Manag. 49 (2008) 3578-3584. doi:10.1016/j.enconman.2008.07.004.

[34] E. Schaltz, A. Khaligh, P.O. Rasmussen, Influence of Battery/Ultracapacitor Energy-Storage Sizing on Battery Lifetime in a Fuel Cell Hybrid Electric Vehicle, IEEE Trans. Veh. Technol. 58 (2009) 3882-3891. doi:10.1109/TVT.2009.2027909.

[35] T. Barlow, S. Latham, I. Mccrae, P. Boulter, A reference book of driving cycles for use in the measurement of road vehicle emissions, (2009) 280.

http://www.trl.co.uk/online_store/reports_publications/trl_reports/cat_traffic_and_the_env ironment/report_a_reference_book_of_driving_cycles_for_use_in_the_measurement_of_ro ad_vehicle_emissions.htm \nhttps://www.gov.uk/government/uploads/system/uploads/att.

[36] EPA, EPA Dynamometer Drive Cycles, (2008). http://www3.epa.gov/nvfel/testing/dynamometer.htm (accessed February 18, 2016).

[37] M. Ehsani, Y. Gao, J.M. Miller, Hybrid Electric Vehicles: Architecture and Motor Drives, Proc. IEEE. 95 (2007) 719-728. doi:10.1109/JPROC.2007.892492.

[38] J.P. Zheng, T.R. Jow, M.S. Ding, Hybrid power sources for pulsed current applications, IEEE Trans. Aerosp. Electron. Syst. 37 (2001) 288-292. doi:10.1109/7.913688.

[39] G. Sikha, B.N. Popov, Performance optimization of a battery-capacitor hybrid system, J. Power Sources. 134 (2004) 130-138. doi:10.1016/j.jpowsour.2004.01.054.

[40] J. Miller, Trends in Vehicle Energy Storage Systems: Batteries and Ultracapacitors to Unite, in: 2008 IEEE Veh. Power Propuls. Conf., IEEE, 2008: pp. 1-9. doi:10.1109/VPPC.2008.4685980.

[41] L. Gao, R.A. Dougal, S. Liu, Power Enhancement of an Actively Controlled Battery/Ultracapacitor Hybrid, IEEE Trans. Power Electron. 20 (2005) 236-243. doi:10.1109/TPEL.2004.839784.

[42] A.M. van Voorden, L.M.R. Elizondo, G.C. Paap, J. Verboomen, L. van der Sluis, The Application of Super Capacitors to relieve Battery-storage systems in Autonomous Renewable Energy Systems, in: 2007 IEEE Lausanne Power Tech, IEEE, 2007: pp. 479-484. doi:10.1109/PCT.2007.4538364. 
[43] S. Lu, K.A. Corzine, M. Ferdowsi, A New Battery/Ultracapacitor Energy Storage System Design and Its Motor Drive Integration for Hybrid Electric Vehicles, IEEE Trans. Veh. Technol. 56 (2007) 1516-1523. doi:10.1109/TVT.2007.896971.

[44] M.B. Camara, H. Gualous, F. Gustin, A. Berthon, B. Dakyo, DC/DC Converter Design for Supercapacitor and Battery Power Management in Hybrid Vehicle Applications-Polynomial Control Strategy, IEEE Trans. Ind. Electron. 57 (2010) 587-597. doi:10.1109/TIE.2009.2025283.

[45] A. Mirzaei, A. Jusoh, Z. Salam, E. Adib, H. Farzanehfard, Analysis and design of a high efficiency bidirectional DC-DC converter for battery and ultracapacitor applications, Simul. Model. Pract. Theory. 19 (2011) 1651-1667. doi:10.1016/j.simpat.2011.04.007.

[46] E. Adib, H. Farzanehfard, Soft switching bidirectional DC-DC converter for ultracapacitorbatteries interface, Energy Convers. Manag. 50 (2009) 2879-2884. doi:10.1016/j.enconman.2009.07.001.

[47] a. Emadi, A New Battery/UltraCapacitor Hybrid Energy Storage System for Electric, Hybrid, and Plug-In Hybrid Electric Vehicles, IEEE Trans. Power Electron. 27 (2012) 122-132. doi:10.1109/TPEL.2011.2151206.

[48] A. Kuperman, I. Aharon, Battery-ultracapacitor hybrids for pulsed current loads: A review, Renew. Sustain. Energy Rev. 15 (2011) 981-992. doi:10.1016/j.rser.2010.11.010.

[49] R. Clague, I. Siera, M. Lamperth, A Novel Hybrid Control Strategy for Maximising Regenerative Braking Capability In a Battery-Supercapacitor Energy Storage System, in: EVS25, 2010: pp. 511-516.

[50] J. Miller, G. Sartorelli, Battery and ultracapacitor combinations-Where should the converter go?, Veh. Power Propuls. .... (2010).

http://ieeexplore.ieee.org/xpls/abs_all.jsp?arnumber=5729216 (accessed December 4, 2013).

[51] R. Carter, A. Cruden, Strategies for control of a battery/supercapacitor system in an electric vehicle, in: 2008 Int. Symp. Power Electron. Electr. Drives, Autom. Motion, IEEE, 2008: pp. 727-732. doi:10.1109/SPEEDHAM.2008.4581315.

[52] A. Kuperman, I. Aharon, A. Kara, S. Malki, A frequency domain approach to analyzing passive battery-ultracapacitor hybrids supplying periodic pulsed current loads, Energy Convers. Manag. 52 (2011) 3433-3438. doi:10.1016/j.enconman.2011.07.013.

[53] Yu Zhang, Zhenhua Jiang, Dynamic power sharing strategy for active hybrid energy storage systems, in: 2009 IEEE Veh. Power Propuls. Conf., IEEE, 2009: pp. 558-563. doi:10.1109/VPPC.2009.5289798.

[54] M.-E. Choi, S.-W. Kim, S.-W. Seo, Energy Management Optimization in a Battery/Supercapacitor Hybrid Energy Storage System, IEEE Trans. Smart Grid. 3 (2012) 463472. doi:10.1109/TSG.2011.2164816.

[55] S. Underwood, Design DC-DC Converters with Reliability in Mind, PowerElectronics.com. (2002).

[56] M.M. B. Eckardt, A. Hofmann, S. Zeltner, Automotive Powertrain DC/DC Converter with $25 \mathrm{~kW} / \mathrm{dm}^{3}$ by using SiC Diodes, Erlangen, 2008. 
[57] Johnson Controls lithium-ion batteries power hybrid luxury SUVs, (n.d.). http://www.jsonline.com/blogs/business/286225371.html (accessed February 18, 2016).

[58] Saft - Mercedes Batteries Contract, (n.d.). http://news.thomasnet.com/companystory/saftmercedes-batteries-contract-531224 (accessed February 18, 2016).

[59] Johnson Controls-Saft Announces BMW Li-ion Battery Contract, (n.d.). http://www.sustainablebusiness.com/index.cfm/go/news.display/id/16942 (accessed February 18, 2016).

[60] W. Sarwar, M. Marinescu, N. Green, N. Taylor, G. Offer, Electrochemical double layer capacitor electro-thermal modelling, J. Energy Storage. 5 (2016) 10-24. doi:10.1016/j.est.2015.11.001.

[61] K.E. Thomas, J. Newman, Heats of mixing and of entropy in porous insertion electrodes, J. Power Sources. 119-121 (2003) 844-849. doi:10.1016/S0378-7753(03)00283-0.

[62] K. Chen, G. Unsworth, X. Li, Measurements of heat generation in prismatic Li-ion batteries, J. Power Sources. 261 (2014) 28-37. doi:10.1016/j.jpowsour.2014.03.037.

[63] T.M. Bandhauer, S. Garimella, T.F. Fuller, A Critical Review of Thermal Issues in Lithium-Ion Batteries, J. Electrochem. Soc. 158 (2011) R1. doi:10.1149/1.3515880.

[64] J. Vetter, P. Novák, M.R. Wagner, C. Veit, K.-C. Möller, J.O. Besenhard, et al., Ageing mechanisms in lithium-ion batteries, J. Power Sources. 147 (2005) 269-281. doi:10.1016/j.jpowsour.2005.01.006.

[65] D. Aurbach, Review of selected electrode-solution interactions which determine the performance of Li and Li ion batteries, J. Power Sources. 89 (2000) 206-218. doi:10.1016/S0378-7753(00)00431-6. 